\title{
ENTRE EL OCIO Y LA FEMINIZACIÓN TROPICAL: CIENCIA, ÉLITES Y ESTADO-NACIÓN EN LATINOAMÉRICA, SIGLO XIX
}

\author{
Jorge Cañizares E. \\ Departamento de Historia - Illinois State University - Campus Box 4420 \\ Normal, IL 61790-4420 (Estados Unidos)
}

\section{RESUMEN}

El aparato teórico de Foucault es inadecuado para explicar procesos de hegemonía cultural en la América Latina decimonónica. Las élites no generaron regímenes discursivos en el sentido que Foucault asigna al término, es decir formas de poder/conocimiento para normalizar, homogenizar y disciplinar las poblaciones de los modernos estados nacionales. Después de la independencia, las élites de los países latinoamericanos encontraron estados para administrar pero naciones todavía por construir. Buscando consolidar los incipientes estados, las élites buscaron distanciarse de los grupos subalternos y en el proceso debilitaron su hegemonía cultural señalando su incapacidad de imaginar comunidades nacionales. Semejante "debilidad imaginativa" de las élites debe encontrarse, en parte, en el contexto internacional en el que les tocó vivir. Asediadas por representaciones anglosajonas y europeas de los trópicos como sitios de ocio y feminización, la tarea de construir discursos nacionales se hizo muy difícil. La autoridad de los discursos científicos post-coloniales sólo podía ser rebatida dentro de la lógica de esos mismos discursos, una lógica que exigía profundizar la construcción de diferencias (raciales, culturales) al interior de los nuevos estados.

\section{SUMMARY}

Foucault's thesis that modernity is characterized by forms of discipline that normalize and control individual conducts and subject positions does not hold for nineteenth-century Latin America. Although the region witnessed a painful and gradual strengthening of the state, it also witnessed the development of weak cultural systems to create national communities out of heterogeneous populations. This cultural debility of the élites can be partially explained by the international intellectual context in which they lived. A dominant Anglo and European view of the "tropics" as places that caused emasculation and sloth contributed to the creation of discurses within the emerging LatinAmerican states that emphasized rather than healed class and racial divisions. In fact gendered representations of the body of subaltern populations were at times useful to justify aggressive policies of colonization and forced labor systems. 


\section{JORGE CAÑIZARES E.}

El presente trabajo busca establecer un diálogo interdisciplinario entre la historia de la ciencia y la historia de la formación del estado-nación en el siglo diecinueve latinoamericano. Existen sin duda muchos puntos de contacto. Quizás el más obvio en el caso latinoamericano es el de la aplicación de conocimientos científicos a las comunicaciones, industria y salud pública que contribuyeron a acelerar la centralización y consolidación del estado. Sabemos sobre el rol unificador que jugaron los ferrocarriles y la telegrafía en la segunda mitad del diecinueve aunque mucho menos sobre la historia de las instituciones y prácticas de los ingenieros que los hicieron posible ${ }^{1}$. Sabemos cada vez más sobre el rol de médicos e higienistas en el desarrollo de nuevas políticas epidemiológicas durante el auge agro-exportador y por ende en la consolidación del estado neo-colonial ${ }^{2}$. Todas estas áreas de estudio prometen un rico diálogo entre las historiografías de la ciencia decimonónica y la de la formación del estado-nación en Latinoamérica.

Un área que en mi opinión es igualmente prometedora y que también todavía está por explorarse con amplitud es la que integra los aportes y perspectivas de los nuevos estudios culturales con aquellos de la historiografía sobre la ciencia decimonónica. Semejante situación es algo paradójica porque uno de los autores cuyo trabajo ha contribuído al origen y desarrollo de estos nuevos estudios culturales, investigando cómo operan discursivamente las formas modernas del poder, ha escrito también extensamente sobre la historia de la medicina y las ciencias sociales. Me refiero a Michel Foucault.

El trabajo de Foucault ha ayudado a elucidar cómo interactúan conocimiento y poder y cómo se constituyen mutuamente. Para Foucault el poder no es una fuerza externa que busca 'reprimir' sino una fuerza interna, 'productiva', que actúa más eficientemente cuando 'normaliza' al individuo y lo auto-disciplina. En su trabajo clásico sobre la historia de la sexualidad, Foucault señala que durante el siglo diecinueve las sociedades europeas no fueron sociedades 'victorianas' reprimidas se-

\footnotetext{
1 JOHnSON, J., (1948) Pioneer Telegraphy in Chile, 1852-1876 (Stanford: Stanford University Press; COATSWORTH, J. H., (1981) Growth against Development: The Economic Impact of Railroads in Porfirian Mexico (DeKalb, Illinois: University of Northern Illinois Press); SAFFORD, F., (1976) The Ideal of the Practical. Colombia's Struggle to Form a Technical Elite (Austin, Texas; University of Texas Press,. Los trabajos de CONTRERAS, M. sobre la historia de la ingeniería minera en Bolivia son dignos de mención pero cubren únicamente el siglo XX: (1994) Tecnología moderna en los Andes: Ingeniería y minería en Bolivia en el siglo XX (La Paz: ILDIS y Biblioteca Minera Boliviana); e "Ingeniería y Estado en Bolivia durante la primera mitad del siglo XX", en Saberes andinos, CUETO, M. (1995) ed. (Lima: Instituto de Estudios Peruanos).

2 STEPAN, N., (1981) Beginnings of Brazilian Science: Oswaldo Cruz, Medical Research and Policy, 1890-1920 (New York: Science History Publications); y (1978) "The Interplay between SocioEconomic Factors and Medical Science. Yellow Fever Research in Cuba and the United States", Social Studies of Science 8: 397-424. Ver también BENCHIMOL, J. L. y TEIXEIRA, L. A., (1990) Cobras, lagartos \& outros bichos (Rio de Janeiro: FIOCRUZ), y la compilación de artículos editados por CUETO, M. (1996) en Salud, cultura y sociedad en América Latina (Lima: Instituto de Estudios Peruanos).
} 
xualmente como tradicionalmente se ha argumentado sino sociedades que se volcaron al estudio del cuerpo y la sexualidad. Médicos y psiquiatras identificaron las desviaciones o casos aberrantes de lo que se llegó a definir como conductas y cuerpos normales. Foucault insiste en que la proliferación de todas estas nuevas áreas de estudio fueron parte del desarrollo de nuevas formas de poder. Los discursos médicos contribuyeron a la consolidación de un nuevo poder que ha operado modulando y creando al individuo-ciudadano. El aporte de Foucault para una nueva historia cultural es el haber señalado cómo regímenes discursivos disciplinan y construyen identidades, es decir, a los sujetos ciudadanos sobre los que el moderno estadonación se articula ${ }^{3}$.

Aplicar este modelo a América Latina en el siglo diecinueve es algo problemático. Después de las guerras de independencia nos encontramos en la región con un panorama en el que en vez de la consolidación del estado-nación presenciamos su desvertebración. Los primeros cincuenta años de vida republicana se caracterizan por la desarticulación de redes comerciales, un regionalismo centrífugo y atomizador, depresión económica, inestabilidad política y la erosión del poder mediador del estado. En vez de un estado-nación centralizador y normalizador emergieron caudillos provinciales, hacendados locales con jurisdicción y poder sobre vastos espacios y comunidades al margen del estado y comunidades indígenas con renovada autonomía política e iniciativa militar4. Es sólo a partir de 1860-1880 cuando el estado recupera algo de su poder centralizador y normalizador; pero aun así se podría muy bien argumentar que el moderno estado-nación se constituye en Latinoamérica tardíamente. La mayoría de países latinoamericanos presenciaron la expansión de derechos ciudadanos (con sus concomitantes discursos normalizadores de mestizaje, indigenismo y nacionalismo) sólo después de la primera guerra mundial y sobre todo

3 The History of Sexuality: An Introduction (New Yordk: Vintage Books, 1980); Discipline and Punish: The Birth of the Prison (New York: Vintage Boosk, 1979). Ver también el trabajo de SAYER, D. y CORRIGAN, P. (1985) The Great Arch: English State Formation as Cultural Revolution (Oxford: Basil Balckwell), que usando el caso inglés hace más explícita la relación entre el control de conductas y la consolidación del estado. Sobre el concepto decimonónico de 'normalidad' y su desarrollo ver HACKING, I. (1990) The Taming of Chance (Cambridge: Cambridge University Press). Relativamente ignorados entre latinoamericanistas pero muy relevantes para aquellos que buscan determinar la forma en que conocimiento y poder se articulan en sociedades coloniales y post-coloniales son los trabajos de COHN, Bernard S. (1996) recientemente coleccionados bajo el título Colonialism and Its Forms of Knowledge: The British in India (Princeton: Princeton University Press).

4 HALPERÍN-DONGHI, T. (1973) The Aftermath of Independence in Latin America (New York: Harper and Row); y BUSHNELL, D. y MACAULAY, N., (1988) The Emergence of Latin America in the Nineteenth Century (New York: Oxford University Press); M. HART, J. (1988) "The 1840s Southwestern Mexico Peasants' War: Conflict in a Transitional Society"; y TUTINO, J. (1988) "Agrarian Social Change and Peasant Rebellions in Nineteenth-Century Mexico: The Example of Chalco", en Riot, Rebellion, and Revolution: Rural Social Conflict in Mexico, Friedrich Katz ed. (Princeton: Princeton University Press) 


\section{JORGE CAÑIZARES E.}

a partir del colapso del modelo agro-exportador neocolonial y el surgimiento del populismo y nuevos proyectos industrializadores.

Es claro que el estado latinoamericano tuvo graves dificultades en liderar procesos de hegemonía cultural a todo lo largo del diecienueve. Varios autores han señalado recientemente cómo gran parte de la historia decimonónica de América Latina se puede caracterizar por el fracaso de hegemonía cultural de las 'élites' frente a sectores 'populares' que continuamente desoyeron, subvirtieron, y parodiaron sus iniciativas y valores. Aunque algunos de estos trabajos ofrecen una imagen romántica y homogeneizan lo 'popular' ocultando sus fisuras, su mérito consiste en señalar la debilidad normalizadora del estado 5 .

La debilidad del poder cultural del estado se revela aun en áreas como la de la salud pública en la que los discursos sociales se prestan fácilmente a ser medicalizados y por tanto a legitimar estructuras socio-económicas. Carl Murdock ha descrito cómo aun en el caso del Chile de Balmaceda, un período que los historiadores han asociado con la emergencia de un estado de corte nacionalista y centralizador, el gobierno fue incapaz de imponer sus políticas epidemiológicas no sólo sobre las mayorías pobres urbanas sino también sobre las élites ${ }^{6}$. Donna J. Guy ha señalado que el estado argentino de fines del dicienueve recurrió mucho más frecuentemente a la fuerza que a la reforma de voluntades individuales a través de la educación pública para regular las conductas de prostitutas y madres lactantes ${ }^{7}$. Marcos Cueto ha descrito el caso de secciones de la población indígena del Puno quienes sólo bien entrado este siglo aceptaron políticas epidemiológicas del estado tendentes a normalizar sus conductas (e.g.: difusión de baños periódicos y cortes de pelo). Cueto presenta

\footnotetext{
5 STAPles, A. "Policía y Buen Gobierno: Municipal Efforts to Regulate Public Behavior, 18211857"; MORgan, T. "Proletarians, Políticos, and Patriarchs: The Use and Abuse of Cultural Customs in the Early Industrialization of Mexico City, 1880-1910"; FRENCH, W. "Progreso Forzado: Workers and the Inculcation of the Capitalist Work Ethic in the Parral Mining District"; y en general todos los otros artículos del libro Rituals of Rule, Rituals of Resistance: Public Celebrations and Popular Culture in Mexico, Beezley, W. H., Cheryl MARTin, E. y E. FrEnCH, W. (1994) eds. (Wilmington, Delaware: Scholarly Resources Books).Ver tambien BEEZLEY, W., (1987) Judas and the Jockey Club and Other Episodes of Porfirian Mexico (University of Nebraska Press). Los diversos artículos del libro recientemente editado por M. JOSEPH, G. y NUGENT, D., (1994) Everyday Forms of State Formation: Revolution and Negotiation of Rule in Modern Mexico (Durham: Duke University Press) exploran el tema del poder-debilidad cultural del estado mexicano durante y después de la Revolución. Ver también BURNS, B., (1980) The Poverty of Progress: Latin America in the Nineteenth Century (Berkeley: University of California Press).

6 Murdock, C. J. (1995) "Physicians, The State and Public Health in Chile, 1881-1891", Journal of Latin American Studies 25, 551-567.

7 CONI, E. and G. (1989) : "Reformers, Public Health, and Working Women", en The Human Tradition in Latin America. The Nineteenth Century, EwELl, J. y BEEZLEY, W. eds. (Wilmington, Delaware: Scholarly Resources Books), 233-48.
} 
este caso como anómalo y digno de ser destacado precisamente por lo poco común ${ }^{8}$. ¿Significa entonces que un estudio à la Foucault de regímenes discursivos que normalizan, de tecnologías políticas que construyen la moderna subjetividad del individuo-ciudadano, de formas de poder/conocimiento en el diecinueve latinoamericano carece de sentido? ¿Qué espacios o alternativas le quedan entonces a una historiografía que busque tender puentes entre el estudio del poder cultural del estado-nación y la historia de la ciencia?

Aunque la ausencia de un estado normalizador diluye un tanto los esfuerzos de vincular el estudio de las ideas científicas del diecinueve latinoamericano a la historia social, en mi opinión una posible avenida para tender puentes de comunicación entre la historiografía de la ciencia y la de los estudios culturales es explorando los regímenes discursivos que modelaron la identidad de las élites. En las páginas siguientes sugiero algunas áreas donde se ha desarrollado o se podría desarrollar este tipo de estudios. Me concentro en particular en dos temas que yo he estudiado en el período colonial tardío y busco elucidar continuidades y/o discontinuidades en esos discursos durante el siglo diecinueve.

\section{CLIMA, RACISMO CIENTIFICO, E IDENTIDAD NACIONAL.}

En el período colonial los discursos médicos de degeneración climática jugaron un rol significativo en la conformación de una identidad criolla. Las teorías médicas clásicas de temperamentos y complexiones permitieron a las élites coloniales el presentar al indígena como un ser flemático que debía ser forzado a trabajar. Criollos y peninsulares se unieron en un esfuerzo por presentar el medio ambiente americano como el causante de una complexión indígena dada al ocio. Los resultados de este ejercicio fueron múltiples y paradójicos. Por un lado, la visión criolla del indio como un ser flemático dio lugar a una identificación histórica con las élites prehispánicas indígenas. Los criollos inauguraron un discurso que enfatizó la creatividad e inteligencia legislativa de los sabios Incas y Aztecas, quienes, se dijo, conocedores de la naturaleza de sus vagos súbditos crearon regímenes de trabajo forzado. Los criollos reforzaron la naturaleza aristocrática y estamental de la sociedad colonial, legitimaron sistemas coloniales de trabajo forzado y racionalizaron su desprecio por el indígena del común al identificarse, irónicamente, con la sabiduría de los pasados gobernantes nobles Incas y Aztecas. El resultado paradójico de esta estrategia discursiva de identidad criolla, basada en última instancia en el uso de la astrología y la medicina galénica, fue el forzar a los intelectuales criollos a desarrollar formas de racismo

8 CuETO, M. (1991) "Indigenismo and Rural Medicine in Peru: The Indian Sanitary Brigade and Manuel Nuñez Buitrón”, Bulletin of the History of Medicine, 65: 22-41. 
científico avant la lettre. Los criollos tuvieron que enfatizar las virtudes de los climas locales para rebatir las acusaciones peninsulares de que la naturaleza americana había degenerado al criollo tanto como al indio. Si en el discurso del indio como ser flemático estaba implícita la noción de un clima degenerador, en el del patriotismo colonial criollo estaba implícita la de América como un paraíso tropical. Para explicar esta forma paralela y contradictoria de entender el clima americano, los criollos se vieron forzados a inventar dentro del marco de tradicionales discursos médicos un cuerpo 'blanco' diferente al del indio con respuestas fisiológicas diferentes al mismo clima. En un esfuerzo por distanciar al criollo del efecto degenerador de los astros y climas americanos, los médicos usaron la ciencia de entonces para separar y discriminar racialmente los cuerpos. Surgió una medicina 'patriótica' que distanció las operaciones orgánicas del cuerpo indio de las del cuerpo de los colonos blancos9.

Las contradicciones y paradojas que he descrito no terminaron con el logro de la independencia y el fin de la crítica peninsular del ser criollo. A todo lo largo del dicienueve presenciamos la creciente obsesión europea con los peligros de los climas tropicales. Dicha obsesión, en mi opinión, contribuyó de la misma manera que en el período colonial a delimitar la identidad de las élites locales y a limitar la constitución de los estados-nación por la necesidad de las élites de distanciarse cultural y biológicamente de las mayorías. Herederas de estados donde el concepto y la realidad de la 'nación' estaban por construirse, las élites generaron estrategias discursivas que en vez de homogeneizar las poblaciones y favorecer el desarrollo de sentimientos nacionales tendieron a dividirlas y separarlas, limitando por tanto la posibilidad del Estado de ejercer hegemonía cultural entre grupos subalternos. Asediadas por representaciones europeas peyorativas de los trópicos, pero al mismo tiempo usufructuando de ellas para justificar regímenes laborales precapitalistas, las élites dividieron discursivamente sus repúblicas en vez de unirlas. En las siguientes páginas describo cómo en el diecinueve, tanto como en el período colonial, el discurso de los trópicos fue usado para justificar regímenes autoritarios y para excluir a vastos sectores de la población de derechos ciudadanos y cómo tambien el uso de dichos discursos generaron paradojas de identidad y ambivalentes pulsiones entre las élites.

Sabemos que la segunda ola imperial europea, esta vez dirigida hacia Asia y Africa, estimuló el desarrollo de nuevas disciplinas y géneros literarios sobre los trópicos. Las representaciones decimonónicas europeas de los trópicos enfatizaron el carácter degenerador del clima, capaz de crear cuerpos propensos al ocio y la promiscuidad ${ }^{10}$. Conocemos relativamente bien las ideas de viajeros y diplomáticos

9 CAÑIzares Esguerra, J., "New world, new stars: Patriotic astrology and the invention of indian and creole bodies in Colonial Spanish America, 1600-1650", American Historical Review 102 (february 1999).

10 Sobre cómo cambian las visiones británicas de los trópicos en el transcurso de la primera mitad del dicienueve, ver CURTIN, P., (1964) The Image of Africa; British Ideas and Action, 1780-1850 (Madi- 


\section{ENTRE EL OCIO Y LA FEMINIZACIÓN TROPICAL: CIENCIA, ÉLITES Y ESTADO-NACIÓN EN...}

extranjeros en América Latina en la segunda mitad del diecinueve acerca de los efectos debilitantes de los climas tropicales. Aun el clima 'moderado' de México (comparado al de Brasil) se convirtió en causa de ansiedad. En 1851 el diplomático norteamericano Branz Mayer argumentaba que "el clima moderado [explica] la vida indulgente, fácil y voluptuosa [de los mexicanos]"11. Para Henry Howard Harper "la laxitud climática [que lo] infecta todo" era el problema fundamental de México. ${ }^{12}$ Como en el período colonial los europeos hicieron también en el diecinueve una clara asociación entre el clima debilitante y la necesidad de implantar regímenes políticos autoritarios en la región. Frente a la holgazanería de los sectores sociales subalternos los viajeros y diplomáticos recomendaron frecuentemente los beneficios de la dictadura. "La dictadura es una forma de gobierno que no es enteramente inadecuada para México", sugería el diplomático norteamericano Harry Frank a principios de este siglo. En su opinión la población era "en general ...totalmente indiferente a qué o quién la gobierna en tanto se le deje holgazanear en una hamaca en paz"13. La víspera de la Revolución Mexicana, Karl Bunz, el representante alemán en México, justificaba el apoyo oficial de su gobierno al régimen de Porfirio Díaz porque consideraba que en la ausencia de Díaz "un zafarrancho descendería sobre México". Para Bunz, la población mexicana "más que ninguna otra necesita una mano fuerte que la mantenga a raya y la eduque para su propio provecho", y la imagen de Díaz ofrecía precisamente eso al capital alemán y a las élites locales ${ }^{14}$.

Tenemos poca evidencia que establezca claramente cómo las élites intelectuales establecieron la relación entre las formas científicas de manejo político y el estudio del clima. Pero me parece que cualquier investigación sobre cómo se construyó la

son: University of Wisconsin Press). Ver también, KENNEDY, D., (1990) "The Perils of the Midday Sun: Climatic Anxieties in the Colonial Tropics", en Imperialism and the Natural World, MACKENZIE, J. M., (Manchester: Manchester University Press); y STEPAN, N., (1993) "Tropical Nature as a Way of Writing", en Mundialización de la ciencia y cultura nacional, LAFUENTE, A., ELENA, A., y ORTEGA, M. L. eds. (Madrid: Editorial Doce Calles,), pp. 495-504.

11 Citado en PIKE, F. B., (1992) The United States and Latin America: Myths and Stereotypes of Civilization and Nature (Texas Univesity Press,), 71.

12 A Journey in Southeastern Mexico: Narrative of Experiences and Observations on Agricultural and Industrial Experiences (Boston, 1910), 65.

13 FRANCK, H. A., (1917) Tramping through Mexico, Guatemala, and Honduras (New York), 279.

14 Citado en KATZ, F., (1981) The Secret War in Mexico: Europe, The United States and the Mexican Revolution (University of Chicago Press), 72. Paul von Hintze, quien remplazó a Bunz durante el régimen de Francisco Madero, consideraba que el fracaso de Madero se originaba en su desconocimiento del hecho que "el pueblo de México no puede vivir bajo otro régimen que no sea el del despotismo ilustrado"; citado en Katz, Ibid, 88. Como nos lo recuerda Paul J. Vanderwood en Disorder and Progress: Bandits, Police, and Mexican Development, (revised and enlarged edition, Wilington, Delaware: Scholarly Resources Books, 1992), existía un abismo entre el Díaz tal como lo imaginaban los diplomáticos alemanes (eficiente y centralizador) y la realidad (en la que ejercía un control tenue sobre las provincias, el estado y la población). 


\section{JORGE CAÑIZARES E.}

identidad de las élites decimonónicas no puede ser separada del estudio de los discursos médicos contemporáneos. La holgazanería aducida como efecto de los climas tropicales contribuyó a legitimar programas conservadores de gobierno de la primera mitad del dicienueve así como también aquéllos de los liberales-positivistas de la segunda mitad del siglo.

No sabemos a 'ciencia cierta' si es que las élites 'neo-borbónicas' de las nuevas naciones andinas usaron formas de climatología colonial para explicar el retiro de los derechos de ciudadanía que previamente habían sido otorgados a la población indígena. Sabemos sin embargo que el tributo fue reinstituido en la Gran Colombia en 1828 una vez que Bolívar hizo pública su convicción de que la extensión de derechos de ciudadanía al indígena había sido un fracaso porque entre otras cosas había suscitado la holgazanería ${ }^{15}$. Sabemos también que los hacendados del Cauca apoyaron entusiásticamente la medida ya que, en su opinión, los derechos de ciudadanía habían ocasionado que los indígenas "se abandon[en] a sus placeres brutales, [se] minor[en] en número y retir[en] de los poblados del Cauca... En muchos pueblos se han entregado a la bebida de licores espirituosos, a que son muy propensos... sin que ninguna necesidad los haga trabajar... Los hacendados han perdido estos brazos y así la agricultura ha padecido mucho"16. Los regímenes conservadores "neoborbónicos" de la primera mitad del diecinueve compartieron con sus predecesores coloniales la misma escéptica y condescendiente actitud de las cualidades y cuerpos de los grupos subalternos.

En la segunda mitad del diecinueve, bajo el nuevo control liberal, es factible encontrar las mismas ansiedades entre élites consumidoras de las representaciones europeas de los trópicos. ¿Hasta qué punto la búsqueda del progreso y primariamente del 'orden' por parte del positivismo latinoamericano fueron batallas lanzadas desde la cúpula para detener la corrupción desatada por los trópicos sobre los cuerpos de la población? ¿Hasta qué punto el positivismo latinoamericano justificó su nuevo discurso de "política científica" al amparo de dichas imágenes?

En su trabajo sobre cambios en los discursos liberales en México a mediados del siglo dicienueve, Charles Hale ha señalado que el liberalismo clásico fue descartado y reemplazado por nuevas versiones que se autodenominaron 'política científica' 17 . Hale describe cómo las versiones liberales de la primera mitad del diecinueve con su énfasis en la promoción de derechos políticos individuales paulatinamente se convirtieron en discursos que pregonaron la subordinación del individuo a los intereses de la sociedad (lo opuesto de lo propuesto por la primera ola liberal). Las nuevas fuerzas 'liberales' presentaron sus doctrinas como científicas, es decir como un retorno a

\footnotetext{
15 Decreto, Gaceta de Colombia, Oct. 19, 1828.

16 "Indíjenas", Gaceta de Colombia, Nov. 9, 1828. (El subrayado es mio)

17. HALE, C. A., (1989) The Transformation of Liberalism in late Nineenth-Century Mexico (Princeton: Princeton University Press,).
} 


\section{ENTRE EL OCIO Y LA FEMINIZACIÓN TROPICAL: CIENCIA, ÉLITES Y ESTADO-NACIÓN EN...}

la realidad empírica y como el abandono de reformas sociales utópicas basadas en unos pocos principios abstractos y dogmáticos. Esta transición del liberalismo al positivismo descrita por Hale buscó crear sociedades autoritarias pero al mismo tiempo 'modernas' y seculares así como justificar el uso de la fuerza aun contra lo que generaciones anteriores de liberales hubiesen sostenido que eran inalienables derechos individuales. Este cambio ideológico entre las nuevas élites necoloniales se hizo en nombre de la evolución y la búsqueda del orden nacionales. Aunque las élites intelectuales mexicanas presentaron esta transición como un avance hacia la construcción de una teoría científica de la política, no podemos deducir a partir del trabajo de Hale cuáles bases empíricas o estudios científicos fueron aducidos para concluir que sólo un régimen de orden y fuerza podría hacer 'progresar' a México. Pero como Alan Knight ha señalado con acierto, es precisamante cuando el régimen neocolonial de Juárez y Díaz se consolida cuando el mito del indígena ocioso y holgazán empieza a cobrar nuevo brío ${ }^{18}$.

Para encontrar las bases empíricas que Hale pasa por alto debemos estudiar la literatura médica de ese período. Un somero estudio de la literatura sobre medicina tropical en el Brasil decimonónico, bastante más desarrollada que la de otros países, parece confirmar mi hipótesis.

El trabajo de Julyan Peard sobre la escuela médica tropicalista de Bahía es un buen punto de entrada a la literatura secundaria, en parte porque parecería refutar mi tesis. Peard señala que un círculo médico compuesto de inmigrantes europeos y criollos en Bahía se opuso a las representaciones dominantes europeas de los trópicos como climas degenerantes. En vez de culpar al clima, los tropicalistas, de acuerdo con Peard, privilegiaron causas sociales y parasitológicas en su esfuerzo por explicar la etiología de las enfermedades tropicales. Las ideas tropicalistas sin embargo no penetraron las escuelas médicas decimonónicas brasileñas. La mayoría de médicos en Brasil, de acuerdo con Peard, siguieron las obras del médico de la corte, José Martins de Cruz Jobim, para quien las enfermedades locales se originaban en el clima de Brasil. Más aun, la escuela tropicalista de Bahía, a pesar de toda su oposición a la etiología y epidemiología europeas, aceptó la tesis de que los organismos se debilitaban en los trópicos. En última instancia lo que diferenció a los tropicalistas de los europeos fue su optimismo anti-determinista que sostenía que era posible 'regenerar' y 'civilizar' Brasil de los efectos negativos de los trópicos. Es más, Peard señala que hacia fines del diecinueve inclusive los tropicalistas de Bahía habían descartado el optimismo que los caracterizó originalmente ${ }^{19}$. El trabajo de Dain Borges confirma y generaliza los hallazgos de Peard. Borges señala que hacia fines del die-

\footnotetext{
18 "Mexican Peonage: What Was It and Why Was It?", Journal of Latin American Studies 18 (1986): 55-56.

19 PEARD, J., (1997) "Tropical Disordes and the Forging of a Brazilian Medical Identity, 18601890", Hispanic American Historical Review 77: 1-44.
} 
cinueve las élites intelectuales de Brasil alcanzaron un consenso pesimista sobre el carácter degenerador de los trópicos ${ }^{20}$.

Es claro que existió una relación entre el surgimiento del positivismo como la ideología dominante de las élites y la aceptación de las doctrinas de los trópicos como lugares de ocio y degeneración. Lo que está por investigar sin embargo es cómo las élites lidiaron con las implicaciones y paradojas de semejante discurso. ¿Buscaron en el racismo científico soluciones que les permitiesen escapar de una visión del medio-ambiente que los condenaba también a la degeneración? ¿Se presentaron las élites criollas como poseedoras de cuerpos con reacciones biológicas diferentes a los trópicos que aquellos de los grupos subalternos? Los estudios de Sidney Chalhoub sobre la política de las campañas de higiene y salubridad en la segunda mitad del diecienueve en Brasil hacen la búsqueda de respuestas aun más difícil.

Chalhoub ha señalado que la forma en que las autoridades de Río de Janeiro atacaron las epidemias de fiebre amarilla que asolaron a Brasil, primero en los cincuenta y después en los setenta, del siglo pasado, fueron bastante diferentes. En la primera ola epidémica de los cincuenta las autoridades instituyeron muy pocas medidas no sólo porque desconocían las verdaderas causas sino también porque la fiebre amarilla afectaba poco a las poblaciones esclavas negras, la base principal del sistema de plantaciones. Es sólo cuando las oligarquías cafetaleras, a la defensiva en las luchas por la abolición de la esclavitud, empezaron a considerar cada vez más seriamente el reemplazar a los esclavos negros con migrantes europeos pobres cuando las autoridades de Río tomaron medidas epidemiológicas mucho más agresivas. En la epidemia de los setenta, como la fiebre amarilla se consideraba que era una enfermedad tropical que afectaba más a los blancos que a los negros, las autoridades de Río decidieron intervenir para salvar a los nuevos inmigrantes europeos ${ }^{21}$. De acuerdo con nuestra revisión del caso brasileño parece ser que, como en el pasado colonial, la respuesta de las élites a las representaciones europeas de los trópicos fue la de enfatizar las diferencias biológicas de las diferentes poblaciones al mismo clima. Pero la estrategia de dividir la población en taxonomías raciales con reaccciones diferenciadas al mismo clima fue, en el caso de fines del diecinueve, la de realzar la vulnerabilidad y no la superioridad corporal blanca a los trópicos como se había hecho en el periodo colonial ${ }^{22}$.

20 BoRgES, D., (1993) “'Puffy, Ugly, Slothful and Inert': Degeneration in Brazilian Social Thought, 1880-1940", Journal of Latin American Studies 25: 235-56.

21 "The Politics of Disease Control: Yellow fever and Race in Nineteenth Century Rio de Janeiro", Journal of Latin American Studies 25 (1993):441-63. Las medidas incluyeron entre otras cosas la eliminación de los 'cortiços' del centro de la ciudad y la movilización forzada de las poblaciones urbanas pobres de mulatos y negros hacia la periferia de la ciudad en las faldas de las montañas (el origen de las modernas favelas).

22 El caso del médico argentino José Ingenieros es característico de como la ansiedad criolla sobre el efecto negativo de los trópicos forzó inclusive a los intelectuales más rígidos a variar las teorías científi- 


\section{ENTRE EL OCIO Y LA FEMINIZACIÓN TROPICAL: CIENCIA, ÉLITES Y ESTADO-NACIÓN EN...}

El estudio de Chalboub abre más preguntas de las que resuelve desde la perspectiva de este trabajo. En primer lugar si el caso del Brasil indica que las élites estaban más preocupadas acerca de su posible degeneración que la de los esclavos negros y mulatos libres, ¿cómo justificaron entonces el uso del argumento de la degeneración tropical para legitimar regímenes autoritarios sobre grupos subalternos? El segundo punto contradictorio a tener en cuenta es que la ansiedad sobre el efecto de los trópicos en los cuerpos blancos se da precisamente en el momento en el que las plantaciones requerían grandes cantidades de migrantes europeos. En el marco del interés de las élites latinoamericanas por atraer migrantes europeos para 'blanquear' sus países, la aceptación de las élites de los trópicos como una zona de peligro no hacía más que erosionar sus esfuerzos ${ }^{23}$. ¿Cómo las élites del Brasil resolvieron esta paradoja?

Quizás una respuesta se encuentre en una doble estrategia de diferenciación racial asumida por las élites. Si bien los grupos blancos se identifican como más propicios a las enfermedades tropicales, los grupos de color (indios, mestizos, mulatos, negros) fueron presentados como más dados a la holgazanería y al ocio. La identificación de los grupos subalternos con pereza y promiscuidad tropical habría permitido a las élites justificar el uso de la coerción extraeconómica para movilizar trabajadores bajo relaciones precapitalistas de producción. La identificación de una susceptibilidad blanca a las enfermedades de los trópicos, por otro lado, habría permitido a las élites, paradójicamente, acelerar y justificar nuevas formas de control urbano y del espacio y por tanto presentarse como fuerzas civilizadoras empeñadas en transformar el medio ambiente frente a potenciales migrantes europeos. Los trabajos de Jeffrey D. Needel y Teresa Meade sobre Río de Janeiro a fines del diecinueve recuentan la virulencia de las estrategias blancas por controlar los espacios urbanos las cuales forzaron a las poblaciones negras y mulatas a abandonar sus 'cortiços' en el centro de la ciudad 24 .

cas raciales europeas. Ingenieros, como buen darwinista social, sostuvo la eventual desaparición de razas 'inferiores' (negros e indios) en el proceso evolutivo. Sin embargo, el ortodoxo y rígido Ingenieros se vio conminado a sostener que en los trópicos latinoamericanos blancos e indios tenían más posibilidades de sobrevivir porque los europeos blancos, al sufrir dificultades de adaptación, perdían vigor y 'efectividad' en la lucha por la supervivencia. Sobre este aspecto del pensamiento de Ingenieros, ver HELG, A., (1992) "Race in Argentina and Cuba, 1880-1930: Theory, Policies, and Popular Reaction", en The Idea of Race in Latin_América, 1870-1940, GRAHAM R., ed. (Austin: University of Texas Press,), 42. Sobre el tema de la diferenciación racial en la medicina tropical ver ANDERSON W., (1996) "Immunities of Empire: Race, Disease, and the New Tropical Medicine, 1900-1920", Bulletin of the History of Medicine 70: 94-118.

23 Sobre las estrategias de 'blanqueo' racial de fines del diecinueve en Latinoamérica ver: SKIDMORE, T., (1974) Black into White: Race and Nationality in Brazilian Thought (New York: Oxford University Press); "Racial Ideas and Social Policy in Brazil, 1870-1940"; y HELG, A. (1992) "Race in Argentina and Cuba, 1880-1930", en The Idea of Race in Latin America.

24 NEEDEL, J. D., (1987) “The Revolta Contra Vacina of 1904: The Revolt against 'Modernization' in 'Belle-Epoque' Rio de Janeiro", Hispanic American Historical Review 67: 233-69; y MEADE, T., (1989) “'Living Worse and Costing More': Resistance and Riot in Rio de Janeiro, 1890-1917”, Journal 


\section{JORGE CAÑIZARES E.}

Los trabajos de Thomas Skidmore y Aline Helg sobre ideas raciales del período neocolonial destacan la creatividad y plasticidad de las élites latinoamericanas frente a las teorías europeas. Skidmore y Helg mantienen que las élites latinoamericanas añadieron y/o descartaron partes de las teorías europeas en la búsqueda por adecuarlas a sus particulares condiciones e intereses aun a riesgo de cometer serias contradicciones. Estos autores señalan, por ejemplo, que frente a la realidad de sus sociedades compuestas de grandes poblaciones negras, indias, y mestizas y frente a la urgencia por 'blanquear' sus poblaciones, las élites blancas latinoamericanas rehusaron las visiones 'anglosajonas' y europeas dominantes que precavían contra los peligros degeneradores de la mezcla biológica de las razas ${ }^{25}$. No hay duda que en su esfuerzo por incorporar teorías médicas sobre degeneración de los trópicos como la base empírica para articular las nuevas 'políticas científicas', las élites fueron igualmente capaces de ofrecer soluciones creativas.

La presente revisión de la literatura sobre medicina tropical en el Brasil decimonónico señala algunas pistas de como las élites latinoamericanas fueron capaces de conectar la medicina tropical y el positivismo en un esfuerzo por consolidar los incipientes Estados de fines del diecinueve. También nos deja ver lo que parece ser una característica de los estados decimonónicos neocoloniales latinoamericanos, que se consolidan a pesar de la ausencia de un discurso que homogenice, normalice y discipline a la 'nación' 26 . Los discursos de las élites tienden a ser excluyentes, a dividir en vez de unir. El estado se consolida al amparo de doctrinas médicas que justifican sistemas autoritarios y regímenes laborales precapitalistas, no así el estado-nación.

\section{HACIA UNA DEFINICION DEL GENERO DE LA NACION}

Otra área de estudio que en mi opinión es relevante para entender las paradojas y tensiones en las construcciones de identidad de las élites es aquella que conecta el clima con el género de la nación. El género del 'cuerpo nacional' puede ser caracterizado como masculino, femenino o andrógino. Las visiones europeas de los trópicos como sitios de indolencia y ocio estuvieron también íntimamente ligadas a la metáfora

of Latin American Studies 21: 241-66; y "Cultural Imperialism in Old Republic Rio de Janeiro: The Urban Renewal and Public Health Project", (1991) en Science, Medicine and Cultural Imperialism, MEADE, T. y WALKER, M. eds. (New York: St. Martin's and Macmillian Press,)

25 Ver nota 22. Para un período algo más tardío ver también STEPAN, N. L., (1991) "The Hour of Eugenics": Race, Gender, and Nation in Latin America (Ithaca, New York: Cornell University Press).

26 Sobre este tema ver el reciente y provocativo libro de THURNER, M., (1997) From Two Republics to One Divided: Contradictions of Postcolonial Nationmaking in Andean Peru (Durham, North Carolina: Duke University Press). 


\section{ENTRE EL OCIO Y LA FEMINIZACIÓN TROPICAL: CIENCIA, ÉLITES Y ESTADO-NACIÓN EN...}

de la feminización ${ }^{27}$. La asociación de los trópicos con sitios húmedos estimuló a que los europeos desde la conquista del continente americano vinculasen al indio y su supuesto primitivismo con su supuesta feminización inducida por el clima. Las teorías médicas galénicas que distinguían los cuerpos masculinos de los femeninos en función del calor vital y humedad de los mismos dieron lugar a que a la América tropical y sus habitantes se los feminice, justificando de esta manera relaciones coloniales de poder ${ }^{28}$.

El caso quizás más conocido sobre cómo intelectuales europeos buscaron la feminización del continente americano es el del naturalista francés Buffon quien en la segunda mitad del dieciocho mantuvo que las Indias occidentales eran una tierra geológicamente nueva que había emergido recientemente de las aguas. Esta teoría permitió a Buffon y a sus seguidores (incluido el belga Cornelius de Pauw) explicar misterios y maravillas del nuevo mundo que por largo tiempo habían deslumbrado a los europeos, entre ellos: por qué los cuadrúpedos americanos eran menos numerosos, pequeños, y feroces y por qué las poblaciones de indios eran racialemente homogéneas, poco numerosas, y permanecían estancadas en estados 'primitivos' de desarrollo29. Buffon y De Pauw sostuvieron que los productos orgánicos de la húmeda América tropical se habían feminizado. Este tipo de teorías, por supuesto, generaron airadas respuestas entre los criollos americanos a fines del dieciocho ${ }^{30}$.

27 STEPAN, N., (1993) "Tropical Nature as a Way of Writing", Mundializacion de la ciencia y cultura nacional, LAFUENTE, A., ELENA A., y ORTEGA, M. L. eds. (Madrid: Doce Calles), 498

28 SCOTT, J. W. (1989) ha señalado que las categorías de género son en general usadas para "significar relaciones de poder". Ver su "Gender: A Useful Category of Historical Analysis", en Coming to Terms: Feminism, Theory, Politics, Elizabeth Weed ed. (New York: Routledge), 94.

29 Antonello Gerbi ha descrito las teorías de Buffon y el debate que ellas suscitaron en La'disputa del Nuevo Mundo': Historia de una polémica 1750-1900, traducción del italiano de Antonio Alastorre (segunda edición, México: Fondo de Cultura Económica, 1982). La misma disputa ha sido estudiada desde una perspectiva diferente (i.e. el debate sobre autoridad historiográfica y fuentes) por mí en: Historical Criticism and the Reconstruction of the Amerindian Past in Europe and Spanish América, 17501800 (Stanford: Stanford University Press, en prensa)

30 Sobre tradiciones intelectuales que asumían que los varones eran más secos que las mujeres ver MACLEAN, I., (1980) The Renaissance Notion of Woman: A Study in the Fortunes of Scholasticism and Medical Science in European Intellectual Life (Cambridge:Cambridge University Press), ch. 3; LAQueUR, T., (1990) Making Sex: Body and Gender from the Greeks to Freud (Camdridge, Mass.: Harvard University Press); y SCHIEBINGER, L., (1989) The Mind Has No Sex? (Cambridge, Mass: Harvard University Press), ch. 3. Laqueur y Schiebinger señalan que hasta fines del dieciocho médicos y anatomistas no consideraban los cuerpos de hombres y mujeres como radicalmente diferentes. Los cuerpos de las mujeres fueron vistos como cuerpos de hombres incompletos cuyos órganos sexuales estaban invertidos por falta de calor vital interno. Desde la antigüedad se refirieron cambios bruscos de hombres a mujeres, y viceversa, debido a la inversión de los órganos sexuales causada por el medio ambiente. Los cronistas españoles relataron con frecuencia inversiones sexuales en el nuevo mundo de sociedades donde los hombres orinaban sentados y las mujeres de pie. Ver por ejemplo SUÁreZ DE PERALTA, J., (1949) Tratado del descubrimiento de las Indias, (México) 5-6; y Conquistador Anónimo, Relación de algunas cosas de la Nueva España y de la gran ciudad de Temistan México, Federico Gómez de Orozco 
Algunos naturalistas criollos no sólo buscaron defender el clima americano contra las críticas de De Pauw y Buffon sino también masculinizar el continente. Un ejemplo típico de esta estrategia fue la historia natural del Reino de Quito del jesuita Juan de Velasco. Velasco, por ejemplo, insistió que leones sin melenas no eran realmente degenerados y feminizados animales en los trópicos como Buffon había sugerido sino pumas, es decir una especie totalmente diferente. La misma estrategia siguió Velasco para refutar a los naturalistas europeos que insistían que las cabras sin 'barba' que abundaban en la región ecuatorial eran chivos sin virilidad. Velasco mantuvo que las 'bestias' americanas eran tan o más temibles que las africanas, que los indios no eran verdaderamante hirsutos sino que se depilaban periódicamente y que la barba no era signo de virilidad sino un mecanismo de eliminación de excrementos humorales. Velasco también atacó agriamente las tesis del Abate Raynal de que las Amazonas no eran las guerreras míticas del Dorado sino indios vestidos de mujeres y aquéllas de De Pauw que sostenían que los indios eran sodomitas ${ }^{31}$.

El esfuerzo de Velasco por virilizar el continente contrastó sin embargo con otras estrategias criollas que consideraron la feminización como una marca de civilización y no de degeneración. Entre los naturalistas criollos que aceptaron la feminización de América se encuentra Francisco Clavijero quien, en vez de rebatir a Buffon respecto al pequeño tamaño y docilidad de los animales de los trópicos americanos, se regocijó de su existencia bajo el argumento de que pequeñez y 'dulzura' eran marcas de civilización y no de barbarie ${ }^{32}$. ¿Por qué ciertos criollos aceptaron sin pelear su propia 'feminización'? Esta estrategia es todavía más sorprendente si tenemos en cuenta que la idea de la feminización tropical del criollo no sólo fue usada por lejanos y oscuros naturalistas belgas y franceses sino sobre todo por peninsulares dispuestos a blandirla para justificar la exclusión criolla de las redes de poder imperial.

El discurso peninsular sobre la feminización del criollo fue parte de una crítica de corte 'republicano' a la ausencia de virtudes cívicas de las poblaciones americanas. Las tradiciones republicanas buscaron en el fasto y la exagerada riqueza la causa de la decadencia social. De la misma manera que se llegó a explicar la decadencia del imperio romano echando mano de la tesis de la corrupción y feminización de sus élites, quienes por dedicarse a los placeres que les ofrecía la gran prosperidad comercial del imperio abandonaron sus virtudes ciudadanas, su vigor militar y por ende su masculinidad frente a las invasiones bárbaras del norte, la crítica republicana del

\footnotetext{
ed. (Mexico, 1961), 68. La idea de que los 'salvajes' y las razas 'primitivas' o 'inferiores' eran seres feminizados ha caracterizado el pensamiento occidental. Sobre este tema ver GILMAN, S. L., (1993) Freud, Race, and Gender (Princeton: Princeton University Press,); y STEPAN, N. L., (1986) "Race and Gender: The Role of Analogy in Science", Isis 77: 261-277.

31 VELASCO, J. De, (1946) Historia del Reino de Quito en la América Meridional, 3 v. (Quito: El Comercio), vol 1, 109, 112, 113, 117, 219, 236.

32 Clavijero, F. J., (1987) Historia Antigua de México (México: Editorial Porrua), 461.
} 


\section{ENTRE EL OCIO Y LA FEMINIZACIÓN TROPICAL: CIENCIA, ÉLITES Y ESTADO-NACIÓN EN...}

criollo encontró en ellos un ejemplo de la feminización producida por la exagerada riqueza y el ocio. Humboldt articuló bien la critica republicana de la masculinidad de las oligarquías criollas, enfrascadas en lujo 'asiático', dedicadas al placer, rodeadas de sirvientes, cuando expresó su escepticismo sobre la posibilidad de que las ciencias arraigaran y prosperaran en las colonias españolas. "La física, las ciencias, que faltan a todos los americanos, no pueden echar raíces profundas sino en una generación robusta y enérgica. ¿Qué se puede esperar de unos jovenes rodeados y servidos de esclavos, que temen los rayos del sol y las gotas del rocio, que huyen del trabajo, que cuentan siempre con el día de mañana, y a quienes aterra las más ligera incomodidad? Estos jóvenes no pueden dar sino una raza afeminada e incapaz de sacrificios que pidan las ciencias y la sociedad"33. Esta crítica llegó a ser generalizada. Ramón Diosdado Caballero, un jesuita catalán en exilio, quien dedicó su vida a la defensa del imperio español y de su acción civilizadora en las colonias, sintetizó en la última década del siglo dieciecho las visiones peninsulares y europeas sobre los criollos de la siguiente manera:

\footnotetext{
"Los criollos tienen las qualidades perversas de los primeros españoles que desenbarcaron en América de los cuales son sus descendientes [pero] sin el corage, la firmeza, la paciencia que tiene el caracter español. Por naturaleza blandos y afeminados pasan la mayor parte de su vida en el ocio y en los placeres. Gustan del fasto pero sin gusto y sin elegancia, se prodigan en la ostentación y el gozo. Por lo general su caracter se reduce a una nulidad grave y preciosa. El amor y la intriga forman toda su ocupación y la virtud predominante de sus mujeres es no hacer gran caso a la castidad ni a ninguna otra virtud doméstica." 34
}

Los debates de la feminización de la población peruana conducidos en Lima a fines del período colonial son ilustrativos de la paradoja criolla que acabo de mencionar.

$33^{\circ}$ Carta de Humboldt a Mutis, Popayan 1801, en Guillermo Hernández de Alba ed., Documentos para la historia de la educación en Colombia 4 v. (Bogota: Editorial Kelly, 1983), 4: 12 (el subrayado es mío). Ver tambien la "Censura del libro de Jose María de Toronje. Descripción geográfica de México (1771), Archivo de la Real Academia de Historia, Madrid, legajo, 11/8013, censura \# 46. Los censores acusan a Toronje de despreciar al criollo: "En toda la obra se hallan descritas las pasiones de mexicanos/nas con una especie de método ofensivo que no deja de hacer ver en ellos el poco cuidado del gobierno, cuya nota es digna de editarse en las producciones publicas... habla de la concupiscencia, poca fe y estafa de las gentes de aquellos paises" (el subrayado es mio).

34 Diosdado Caballero, R., "Defensa de los Criollos Americanos". Archivo Provincial de Tole do de los Jesuitas, Colegio San Ignacio de Loyola, Alcala de Henares, Estante 4A, caja 17, carpeta 10. El texto en italiano dice lo siguiente: "Il creoli hanno tutte la cative qualita di quei primi Spagnuoli che sbarcarono in America e dai quali sono discesi senza quel coragio, quella fermezza, e quella pazienza che formano in gran parte il carattere Spagnuolo. Naturalmente molli, ed effeminati passano la maggior parte della vita nell'ozio, e nei piaceri. Pieni di fasto ma senza gusto, e senza eleganza, prodighi per ostentazione, piutosto per godimenti; generalmente tutto il suo carattere si reduce ad una nullita grave, e prezioza. L'amore, el intrigo formano tutta la loro ocupazione; e le virtú predominanti delle donne no sono gran fatto la castita, ne l'altre virtu domestiche." (Fol 1) 


\title{
JORGE CAÑIZARES E.
}

A fines del siglo dieciocho los peninsulares buscaron presentar a los criollos peruanos como promiscuos y extremadamente feminizados. Hesperófilo, un anónimo peninsular colaborador de las páginas del Mercurio Peruano, por ejemplo, lanzó en 1792 una defensa del clima del Perú contra aquellos que "por lo común [creen] que su temperamento propende a debilitar la constitución física de los hombres." 35 A pesar de su rechazo al determinismo climático europeo, Hesperófilo presentó a los criollos como promiscuos y por tanto con una tendencia marcada a envejecer. Hesperófilo insistió que el envejecimiento prematuro de los criollos era el resultado de su 'enervación' debido al uso descontrolado de su sexualidad. Mientras para Hesperófilo los peninsulares "a penas se atreverán a mendigar una limosna a Priapo", los criollos eran unos seguidores de la "diosa de Chipre". La falta de control de los criollos sobre su sexualidad los colocaba decididamente en el campo de los seres femeninos incapaces de dominar y domesticar sus cuerpos. En el marco de las doctrinas médicas clásicas, en las que operaba la lógica del argumento de Hesperófilo, el uso indiscriminado de líquidos seminales era la causa más importante de feminización e inversión sexual ${ }^{36}$.

Pocos años más tarde, Simón Ayanque reavivó la tesis de la degeneración y feminización inducida por los trópicos y presentó al Perú como una tierra de indolentes, corruptos arribistas y, particularmente, homosexuales. De acuerdo con Ayanque todo en el Perú estaba invertido: mulatos y mestizos pasaban como blancos, y hombres se conducían como mujeres:

\author{
Verás ciertos maricones \\ Plaga del clima Limeño \\ Con voces afeminadas \\ Cotillas, y barbiquejos. \\ Verás que lavan, planchan, \\ Almidonan con esmero, \\ Y estiran; quando debieran \\ Estar estirados ellos. \\ Verás el odio implacable, \\ Y sumo aborrecimineto \\ Que tienen a las mugeres (sic)... ${ }^{37}$
}

35 Hesperófilo, "Carta escrita a la sociedad sobre la longevidad de algunos peruanos, que se relaciona en prueba de la salubridad del temperamento de estos países," Mercurio Peruano 5 (1792): 164.

36 BROWN, P. (1988) ha señaldo que las élites romanas educadas en el discurso médico galénico temían los orgasmos porque los vaciaba de calor vital y los predisponía a la feminización y al cambio sexual. Ver su The Body and Society: Men, Women, and Sexual Renunciation in Early Christianity (New York: Columbia University Press), 10-11.

37 TERRALlA Y LANDA, E. de, (1798) (alias Simon Ayanque), Lima por dentro y fuera: en consejos economicos, saludables, politicos y morales que da un amigo a otro con motivo de querer dexar la Ciudad de Mexico por pasar a la de Lima (Madrid), 73 (el subrayado es mio). 


\section{ENTRE EL OCIO Y LA FEMINIZACIÓN TROPICAL: CIENCIA, ÉLITES Y ESTADO-NACIÓN EN...}

Es en el contexto de ataques peninsulares a la virilidad del criollo donde el médico limeño Hipólito Unanue presentó sus doctrinas sobre el efecto del clima tropical sobre los peruanos. Unanue estudió las relaciones entre el clima y el cuerpo buscando refutar a Buffon y sus seguidores; sin embargo, el médico limeño no negó el efecto feminizante del clima del Perú, cuya humedad hacía afeminados y ociosos a los hombres; Unanue no tuvo empacho en presentar a los criollos como marcadamente 'sensibles' y usó el caso de los continuos ataques histéricos de su recientemente fallecida esposa para demostrar la marcada 'excitabilidad' nerviosa de todos los peruanos ${ }^{38}$. Dicho argumento también le permitió a Unanue el justificar como terapeútico el uso del látigo contra los indios quienes, de acuerdo con Unanue, eran dueños de una exquisita sensibilidad. La feminización del indio fue usada por criollos como Unanue para justificar regímenes coloniales de poder ${ }^{39}$. Lo paradójico de la posición de Unanue fue que su climatología no excluyó al varón criollo.

Aun aquellos criollos peruanos que descartaron abiertamente teorías climatológicas para explicar conductas sociales subrayaron la feminización del varón limeño. José Ignacio Lequanda, por ejemplo, mientras atacaba en 1794 en las páginas del Mercurio Peruano a europeos como De Pauw que "[han] llegado al extremo de confundir[nos] con Patagones y Eskimauses [que son razas embrutecidas por el clima] ...poniendo en un mismo paralelo al Español Americano, con el Indio más inculto de la Sierra"40, aceptaba al mismo tiempo la subordinación del varón criollo frente a sus mujeres. Irónicamente Lequanda usó la feminización criolla para descartar el efecto del clima sobre los cuerpos. Argumentó que de acuerdo con la climatología europea, siendo el Perú un país templado, se debería esperar que todas las mujeres del país sean 'libres' a diferencia de aquellas de los "países frios..., que son señoras de los hombres... y [de] los cálidos [que son] esclavas"41. El Perú desmentía la climatología europea porque a pesar de su clima templado las Indias eran esclavas de los indios y las criollas dominaban a los pasivos afeminados criollos.

¿Por qué hubo tantos criollos dispuestos a aceptar las conclusiones de los europeos sobre la feminización de los trópicos? En mi opinión dichos criollos no hicieron más que aceptar las visiones favorables de lo femenino como marca de civilización y no barbarie que caracterizó a muchos discursos ilustrados. Estudiosos del siglo de las luces, por ejemplo, han resaltado la asociación entre progreso y la domesticación-

38 Observaciones sobre el clima de Lima y sus influencias (segunda edición, Barcelona, 1815), 81-2 (humedad que genera ocio en toda la población), 83-4 (feminización de la población), 100-101 (excitabilidad de los peruanos similar a la de mujeres histéricas).

39 Ibid, 139-40. Moxó, B. M., (1837) Cartas Mexicanas (Génova) justifica también el uso del látigo para curar la exquisita sensibilidad del indio inspirado en sus lecturas de Unanue (313-14) y añade que los indígenas tienen tan poca atención mental como las mujeres (323).

40 LEQUANDA, J. I. de, (1794) "Discurso sobre el destino que debe darse a la gente vaga que tiene Lima," Mercurio Peruano 10: 105.

41 Ibid, 116. 


\section{JORGE CAÑIZARES E.}

feminización de las pasiones en los discursos dieciochescos sobre desarrollo económico. Albert Hirschman ha demostrado que la economía política del dieciocho sostuvo que las sociedades comerciales eran el resultado del abandono de las pasiones agresivas y guerreras por unas más 'dulces' y gentiles asociadas con el carácter femenino ${ }^{42}$. Es en este contexto en el que se puede entender la decisión de Clavijero de no buscar la virilización de la naturaleza mexicana. G. J. Barker-Benfield, por otro lado, ha descrito cómo las teorías orgánicas de Haller que llevaron al descubrimiento de la 'sensibilidad' nerviosa fueron usadas para explicar no sólo conductas y patologías 'femeninas' sino tambión el genio romántico ${ }^{43}$. De nuevo, en el marco de dichas teorías la estrategia de Unanue de presentar al criollo como dueño de una exquisita sensibilidad nerviosa cobra sentido. Esta ambivalencia que caracterizó la cultura ilustrada y que atrae cada vez más la atención de los estudiosos, estimuló a algunos criollos a feminizar abiertamente a sus naciones ${ }^{44}$.

Lo llamativo de las estrategias que aquí he esbozado para el período colonial tardío es que son complejas y variadas y no buscan el rechazo absoluto de los discursos europeos de la feminización de los trópicos. El discurso de la feminización climática como lo señala el caso de Unanue fue atractivo para las élites porque les permitió justificar procesos de dominación interna. Las élites latinoamericanas usaron el tema de la humedad y feminización para explicarse de alguna manera el origen de las divisiones raciales y de clase en el interior de sus propias sociedades y para justificar el uso de la coerción extraeconómica de grupos subalternos. Los problemas de identidad que estas estrategias seguramente suscitaron dentro de la comunidad criolla fueron resueltos echando mano de las asociaciones ilustradas positivas entre lo femenino y las fuerzas de la civilización. Pero ¿qué pasó más tarde en el período nacional decimonónico? A continuación esbozo algunas ideas.

El trabajo de Fredrick B. Pike sobre las representaciones norteamericanas decimonónicas de los latinoamericanos es provocativo y sumamente relevante para entender las paradojas y tensiones criollas republicanas acerca de la posible feminización de sus naciones en los trópicos. Pike ha señalado que los norteamericanos, a lo largo del siglo diecinueve, construyeron una imagen tanto de las élites como de las mayorías pobres latinoamericanas como seres cercanos al 'estado de la naturaleza', dependientes y afeminados. Para los norteamericanos los latinos eran seres sensua-

42 HIRSCHMAN, L. A. (1977) The Passions and the Interests: Political Arguments for Capitalisms before Its Triumph (Princeton: Princenton University Press,. En la misma linea de Hirschman ver tambien TOMÁSELLI, S., (1985) "The Enlightenment Debate on Women", History Workshop Journal 20: 101-24.

43 BARKER-BENField, G. J., (1992) The Culture of Sensibility: Sex and Society in Eighteenth-Century Britain (Chicago : University of Chicago Press).

44 Ver por ejemplo los trabajos de Goodman, D., (1994) The Republic of Letters: A Cultural History of the French Enlightenment (Ithaca, New York: Cornell University Press); y la serie de artículos que acaban de aparecer en Eighteenth-Century Studies, Volume 30, Number 1, Fall 1996. 


\section{ENTRE EL OCIO Y LA FEMINIZACIÓN TROPICAL: CIENCIA, ÉLITES Y ESTADO-NACIÓN EN...}

les, irracionales e infantiles; dependientes del trabajo de otros y de los favores del estado, comunidades y dioses católicos (vírgenes y santos); incapaces de transformar sus fronteras; incapaces de 'penetrar' tierras vírgenes para inseminarlas, transformarlas y civilizarlas. Pike insiste en que estas representaciones tuvieron un claro carácter sexual: tanto los latinoamericanos como los indios y los negros fueron presentados como razas femeninas inferiores que ocupaban tierras y fronteras que sólo una raza de hombres independientes y varoniles como los anglosajones podían 'penetrar' y transformar ${ }^{45}$. Lo que quiero rescatar del trabajo de Pike para el próposito de este artículo es que las visiones anglo-sajonas protestantes de América Latina no necesitaron el respaldo de la climatología tropical para feminizar la región y que tuvieron gran auge y popularidad en países europeos cuando lanzaron su expansión imperialista a Africa y Asia a finales del siglo diecinueve buscando imitar la virilidad de los yankis contra búfalos, indios y mexicanos en el Oeste. Cabe preguntarse cuál fue la respuesta de las élites latinoamericanas frente a semejantes discursos.

Es claro que el liberalismo decimonónico buscó virilizar Latinoamérica. Los liberales buscaron deshacer las diversas formas de dependencia (estado, religión y formas comunitarias de propiedad) que de acuerdo con los 'anglosajones' tendían a feminizar a la población de la región. Bajo la égida de los liberales-positivistas las élites buscaron imitar las estrategias masculinas norteamericanas de 'penetración' de tierras 'vírgenes' ocupadas por razas femeninas indígenas tanto en las pampas argentinas, como en el sur de Chile, o como en el norte de México. La estrategia liberal parecería obvia y simple. La consecución de la modernidad, el progreso y transformación de la naturaleza latinoamericana involucraba la masculinización de su población y/o la eliminación de aquellos sectores afeminados e inferiores. Sin embargo parece ser que las cosas no fueron tan simples.

Doris Sommer ha señalado el rol crucial que jugaron las novelas decimonónicas en América Latina para consolidar las estrategias de las élites de integración e identidad nacional. Según Sommer las novelas latinoamericanos auspiciadas por las élites liberales a partir de los años 1850 feminizaron al héroe y masculinizaron a la heroína. Novelas tales como María de Jorge Isaacs, Amalia de José Mármol, o Enriquillo de Manuel de Jesús Galván, fueron metáforas a soluciones de problemas nacionales. Las novelas fueron historias que buscaron integrar racial, territorial y políticamente cada una de las diversas naciones latinoamericanas usando la metáfora de parejas distanciadas que vencen obstáculos para lograr la consumación de su amor y deseo. Después de cerca de medio siglo de luchas intestinas y el liderazgo militar de caudillos, las naciones latinoamericanas al encontrarse desvertebradas y en caos buscaron en las novelas nacionales un nuevo género literario para reemplazar al héroe militar

45 PIKE, F. B., (1992) The United States and Latin América: Myths and Steroptypes of Civilization and Nature (Austin, Texas: University of Texas Press), passim, esp. 7, 26, 77, 81, 101, 114, 135. 


\section{JORGE CAÑIZARES E.}

de las primeras épicas nacionales con otro más interesado en construir hogares que en pelear grandes batallas. Sommer señala que las nuevas novelas por lo general presentan héroes con cuerpos delicados y sensibilidad femenina cortejando a heroínas activas y audaces. De acuerdo con Sommer la feminización del héroe fue una estrategia liberal deliberada que buscó señalar nuevas prioridades a estados nacionales ansiosos por acabar el culto a los viriles caudillos militares y por iniciar un período de población, reproducción y colonización pacífica del territorio ${ }^{46}$. Como en el pasado colonial, la utopía de transformar los nuevos espacios nacionales en emporios comerciales generó un discurso que huyó del ideal masculino del patriota armado y buscó feminizar a la población para emprender las tareas de poblamiento y desarrollo económico.

Como en el período colonial tardío podemos encontrar en las repúblicas latinoamericanas decimonónicas dos pulsiones contradictorias. Por un lado, las élites buscan responder a los discursos anglo-europeos cuyo desprecio por las nuevas naciones se manifestó en discursos que las femininizaban. Frente a estos discursos existe un claro esfuerzo por construir discursos que masculinicen, virilicen la imagen de los balbuceantes Estados. Las élites usan entonces el discurso de la feminización para justificar el asalto a los grupos subalternos, ya sea para conminarlos a trabajar a latigazos o para eliminarlos físicamente en la búsqueda de la expansión de las fronteras. Pero por otro lado, las demandas locales exigen a las élites no descartar los discursos de feminización para construir su propia identidad. En los casos que he discutido las élites buscaron identificar lo femenino con valores civilizadores y comerciales para traer prosperidad y paz a sus países. Como en el caso de la ociosidad y degeneración tropical, la feminización del espacio y poblaciones latinoamericanas generó ambivalencias y paradojas en la construcción de identidad de las élites.

\section{CONCLUSIONES}

$\mathrm{Al}$ comenzar este trabajo señalaba que el aparato teórico de Foucault era inadecuado para explicar los procesos de hegemonía cultural en la América Latina decimonónica. Las élites no generaron regímenes discursivos en el sentido que Foucault asigna al término, es decir formas de poder/conocimiento para normalizar, homogeneizar y disciplinar las poblaciones de los modernos estados nacionales. Después de la independencia, las élites de los países latinoamericanos encontraron Estados para administrar pero naciones todavía por construir. Buscando consolidar los incipientes estados, las élites buscaron distanciarse de los grupos subalternos y en el proceso

\footnotetext{
46 SOMmER, L. D., (1991) Foundational Fictions: The National Romances of Latin America (Berkeley: University of California Press).
} 
ENTRE EL OCIO Y LA FEMINIZACIÓN TROPICAL: CIENCIA, ÉLITES Y ESTADO-NACIÓN EN...

debilitaron su hegemonía cultural señalando su incapacidad de imaginar comunidades nacionales. Semejante 'debilidad imaginativa' de las élites debe encontrarse, en parte, en el contexto internacional en el que les tocó vivir. Asediadas por representaciones anglosajonas y europeas de los trópicos como sitios de ocio y feminización la tarea de construir discursos nacionales se hizo muy difícil. La autoridad de los discursos científicos post-coloniales sólo podía ser rebatida dentro de la lógica de esos mismos discursos, una lógica que exigía profundizar la construccción de diferencias (raciales, culturales) al interior de los nuevos estados. 